\title{
An evaluation of simultaneously administered free and intrinsic factor bound radioactive cyanocobalamin in the diagnosis of pernicious anaemia in the elderly
}

\author{
M. S. PATHY, S. KIRKMAN, AND M. J. MOLLOY
}

From the University Hospital of Wales, Heath Park, Cardiff CF4 $4 X W$, and the South Wales Radiotherapy and Oncology Service, Velindre Hospital, Cardiff CF4 $7 X L, U K$

SUMMARY The definitive diagnosis of pernicious anaemia (PA) in the elderly is by no means always straightforward, particularly when inappropriate medication has been introduced before the institution of specific investigatory procedures. A detailed haematological study was carried out on 301 patients aged 60-95 with a serum $B_{12}$ concentration at the laboratory's lower level of normal of $150 \mathrm{ng}$ per litre (Euglena gracilis assay).

The diagnosis of PA was based on strict predetermined haematological criteria. All patients were subsequently studied by the simultaneous oral administration of the dual isotopes ${ }^{57} \mathrm{Co}-$ labelled $B_{12}$ bound to intrinsic factor and free ${ }^{58} \mathrm{Co}$-labelled $\mathrm{B}_{12}$ (Dicopac test), and urine was collected over 24 hours after an intramuscular dose of $1 \mathrm{mg}$ nonradioactive $B_{12}$ for estimation of the ${ }^{57} \mathrm{Co} /{ }^{58} \mathrm{Co} \mathrm{B}_{12}$ ratio; 255 patients satisfied all criteria for final analysis.

The Radiochemical Centre, Amersham suggests an upper limit of the normal range for the ${ }^{57} \mathrm{Co} /{ }^{58} \mathrm{Co}$ ratio of $1 \cdot 3$ with a lower limit for PA of $2 \cdot 0$. We were unable to show a sharp borderline in the ${ }^{57} \mathrm{Co} /{ }^{58} \mathrm{Co} \mathrm{B}_{12}$ ratio between those patients shown by other criteria to have PA and those who do not have PA; $34 \%$ of the 71 established patients had a ratio below $2 \cdot 0$. From our series a ratio borderline drawn at 1.4 gave only one talse negative (1.4\% of the PA group). Of the 175 non-PA cases, nine (5\%) gave false positive results; four of these had ${ }^{58} \mathrm{Co}$ excretion levels high enough to make misdiagnosis unlikely.

In a proportion of patients the ${ }^{57} \mathrm{Co} /{ }^{58} \mathrm{Co} \mathrm{B}_{12}$ ratio was estimated at regular intervals for 36-hour periods. Maximum accuracy of isotope measurement on a single specimen was obtained 8-20 hours after isotope dosing.

The Dicopac investigation is a useful simple screening test in the differential diagnosis of patients with a megaloblastic bone marrow and combined low serum $B_{12}$ and folate concentrations. When carried out by the standard technique, the degree of discrimination between normal and abnormal ratios is of limited diagnostic significance in one-third of patients.

The definitive diagnosis of pernicious anaemia (PA) is not always straightforward. The elderly are particularly prone to multiple haematinic deficiencies (Evans et al., 1968), and folate-deficient megaloblastic anaemia with secondary $\mathrm{B}_{12}$ malabsorption is not uncommon. The administration of vitamin $\mathrm{B}_{12}$ to older subjects is widespread and is considerably in excess of the incidence of proven PA in the

Received for publication 11 September 1978 community (Cochrane and Moore, 1971). The introduction of the Schilling (1953) test provided a valuable tool for measuring $B_{12}$ absorption, but the practical difficulty of precise urine collection and the effects of renal disease on urinary $B_{12}$ excretion limit its application in the aged.

Concurrently administered intrinsic factor (IF) will improve the absorption of cyanocobalamin in patients with PA (Heinle et al., 1952; Schilling, 1953) or after total gastrectomy (Halsted et al., 1954). To overcome the disadvantages of administering radioactive $B_{12}$ with and without IF at a minimal 
three-day interval, Katz et al. (1963) introduced a dual isotope technique involving the simultaneous administration of ${ }^{60} \mathrm{Co}$-labelled cyanocobalamin saturated with IF, and free ${ }^{57} \mathrm{Co}-$ labelled cyanocobalamin. Bell et al. (1965) reduced the radiation dose by using ${ }^{57} \mathrm{Co}-$ labelled $\mathrm{B}_{12}$ bound to IF and ${ }^{58} \mathrm{Co}$ labelled free $B_{12}$.

This report compares the value of the simultaneous administration of free and IF-bound radioactive cyanocobalamin with other diagnostic criteria (vide infra) in establishing the diagnosis of PA in elderly subjects with low serum $\mathrm{B}_{12}$ concentrations.

The diagnosis of PA was regarded as validated if all the following five criteria were satisfied:

1 an MCV of $100 \mathrm{fl}$ or above;

2 a serum $B_{12}$ level of $100 \mathrm{ng} / \mathrm{l}$ or less;

3 biopsy evidence of an unequivocal megaloblastic bone marrow;

4 absence of free gastric hydrochloric acid before and after pentagastrin stimulation;

5 a reticulocyte response to a single therapeutic dose of $250 \mu \mathrm{g}$ vitamin $\mathbf{B}_{12}$ of at least $5 \%$ of the red cell count (above the pretreatment level) and a rise in the red cell count by the second to third week.

It is appreciated that a reticulocyte response to a microdose of $5 \mu \mathrm{g}$ vitamin $\mathrm{B}_{12}$ would have provided a less debatable criterion. However, all patients with a megaloblastic anaemia and a combination of low serum folate and $B_{12}$ concentrations were given a daily intramuscular dose of $200 \mu \mathrm{g}$ folic acid for nine days. An absent reticulocyte response to folic acid with a subsequent response to a single dose of $250 \mu \mathrm{g} \mathrm{B} \mathrm{B}_{12}$ was accepted as part of criterion No. 5.

The presence of serum IF antibody is of diagnostic significance, but the absence of this antibody in the serum does not exclude a diagnosis of PA. The mean frequency of serum IF antibody in 10 separate series of patients with PA (quoted by Chanarin (1969)) was $54 \%$.

\section{Patients and methods}

Of the initial 301 patients, 255 aged $60-95$ whose serum $B_{12}$ concentrations were $150 \mathrm{ng} / \mathrm{l}$ or less satisfied all criteria for inclusion in this study. Serum $B_{12}$ levels were determined by the Euglena gracilis assay method of Hunter et al. (1956) modified from the method of Ross (1952). Mollin and Ross (1957) noted serum $\mathbf{B}_{12}$ concentrations in untreated PA ranging from 10 to $110 \mathrm{ng} / \mathrm{l}$, and Spray and Witts (1958) found values between 20 and $170 \mathrm{ng} / \mathrm{l}$. Although subsequent data analyses showed that no patient with untreated PA in this series had a serum $B_{12}$ concentration above $82 \mathrm{ng} / \mathrm{l}$, we studied all patients with concentrations at or below the laboratory's lower limit of their normal range of $150 \mathrm{ng} / 1$. Investigations before isotope studies included a haemoglobin estimation, red and white whole and differential counts, MCV, blood urea, serum electrolytes, LDH and HBD enzymes, plasma proteins and electrophoresis, serum iron and total iron binding capacity (TIBC) (Nakamura et al., 1965) and serum folate (Waters and Mollin, 1961), and vitamin $\mathbf{B}_{12}$ assay with Euglena gracilis (Hunter et al., 1956). All glassware used for serum iron, TIBC, folate, and $B_{12}$ estimations was new (that is, unused). Bone marrow films and serum for IF and parietal cell antibodies were examined in all patients. All blood sampling was carried out at about 0900 hours after overnight fasting. In subjects with a megaloblastic marrow histology, free $\mathrm{HCl}$ was estimated after the administration of $6 \mu \mathrm{g}$ pentagastrin per kg body weight.

Free and bound radioactive cyanocobalamin, prepared by the Radiochemical Centre in capsule form and described as a Dicopac kit, were used throughout the study. The ${ }^{57} \mathrm{Co}-$ labelled $\mathrm{B}_{12}$ bound to IF had a nominal activity of $0.5 \mu \mathrm{Ci}$, and the free ${ }^{58} \mathrm{Co}$-labelled $\mathrm{B}_{12}$ had a nominal activity of $0.8 \mu \mathrm{Ci}$.

Outpatients were admitted to hospital for 72 hours for isotope studies. After overnight fasting the two isotopes were administered simultaneously by mouth. Two hours later a flushing dose of $1 \mathrm{mg}$ non-radioactive vitamin $\mathbf{B}_{12}$ was given intramuscularly, and food was permitted. Urine was collected over the 24 hours after isotope dosing. The significant energy difference in the gamma emissions of the two isotopes allows the activity of each isotope to be separately detected and measured in the same urine sample. However, the accuracy with which the results can be quoted varies considerably. If, for PA, the ${ }^{58} \mathrm{Co}$ excretion approaches zero but the ${ }^{57} \mathrm{Co}$ level is normal, the ratio approaches infinity, and although the result of the test is not in doubt, a value for the ratio cannot be quoted with confidence. For a specimen containing low levels of both isotopes, neither the values of the ${ }^{58} \mathrm{Co}$ and ${ }^{57} \mathrm{Co}$ levels nor the value of the ratio can be quoted accurately. The technique has the advantage that when complete urine collection is difficult (for example, in confused or incontinent patients) and values for the total excretion cannot be obtained, useful information about the ${ }^{57} \mathrm{Co} /{ }^{58} \mathrm{Co}$ ratio can still be gained from a single specimen. To establish the time at which to collect the specimen that would give maximum accuracy, individual samples were collected over 36 hours from nine patients with PA and from 15 non-PA patients. 


\section{Results}

PA was the most frequent single cause of severe vitamin $B_{12}$ depletion among our patients. Table 1 gives mean values of relevant investigations in the PA and non-PA groups.

Table 1 Summary of relevant investigations of $P A$ and now-PA subjects (mean values)

\begin{tabular}{|c|c|c|}
\hline Investigation & $P A$ & Non-PA \\
\hline $\begin{array}{l}\text { Hb }(\mathrm{g} / \mathrm{dl}) \\
\text { RBC }\left(10^{12} / 1\right) \\
\text { WBC }\left(10^{\circ} / 1\right) \\
\text { MCV (fl) } \\
\text { *Serum } \text { B }_{12}(\mathrm{ng} / \mathrm{l}) \\
\text { Serum folate }(\mu \mathrm{g} / \mathrm{l}) \\
\text { Serum iron }(\mu \mathrm{mol} / \mathrm{l}) \\
\text { Serum TIBC }(\mu \mathrm{mol} / \mathrm{l}) \\
\text { LDH (IU/1) } \\
\text { HBD (IU/l) } \\
\text { IF antibodies }(\%) \\
\text { PC antibodies }(\%)\end{array}$ & $\begin{array}{c}6 \cdot 1 \\
2 \cdot 1 \\
3 \cdot 8 \\
119 \\
61 \\
8 \cdot 4 \\
11 \cdot 5 \\
72 \cdot 0 \\
2560 \\
2054 \\
52 \cdot 0 \\
76 \cdot 0\end{array}$ & $\begin{array}{c}10 \cdot 6 \\
3 \cdot 6 \\
7 \cdot 1 \\
84 \cdot 0 \\
102 \\
4 \cdot 5 \\
7 \cdot 4 \\
82 \cdot 3 \\
308 \\
445 \\
0 \cdot 0 \\
27 \cdot 0\end{array}$ \\
\hline
\end{tabular}

*Subjects with $B_{12}$ levels below $50 \mathrm{ng} / \mathrm{l}$ quoted by laboratory as 'less

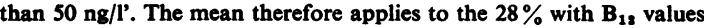
of $50 \mathrm{ng} / 1$ or above.

The raised serum $\mathrm{LDH}$ and HBD levels in patients with a megaloblastic anaemia fell to normal within 14 days of initiating specific therapy. The megaloblastic anaemias produce a higher mean rise in LDH and HBD levels than any other disease process (Pathy and Davies, 1971).

Of the iron-deficient non-PA patients, $38 \%$ had positive serum parietal cell antibodies, but these were detected in only $8.5 \%$ of patients with neither PA nor iron deficiency.

The probable factors for low serum $B_{12}$ levels in a proportion of the 184 non-PA subjects are given in Table 2. Four patients with a serum $B_{12}$ level below $50 \mathrm{ng} / \mathrm{l}$ also had serum folates of $0.5,0.75,1.0$, and $1.5 \mu \mathrm{g} / 1$ respectively and a megaloblastic bone marrow. Daily doses of $200 \mu \mathrm{g}$ folic acid subcutaneously produced no reticulocyte response on the fifth to ninth days, but administration of a single

Table 2 Associated factors in 184 non-PA subjects with serum vitamin $B_{12}$ levels of $150 \mathrm{ng} / \mathrm{l}$ or less

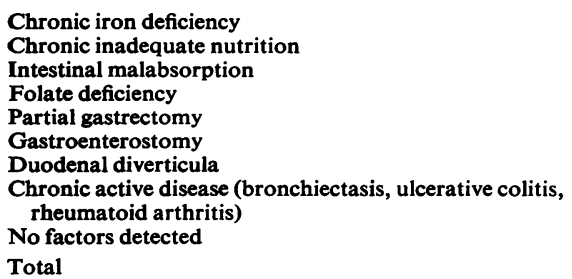

40
37
31
26
9
2
3
7
30
184

dose of $250 \mu \mathrm{g}$ vitamin $\mathrm{B}_{12}$ produced a prompt reticulocyte response (maximum mean rise $23 \%$ ) with a rise in the red cell count and haemoglobin. These four subjects were included in the 71 patients diagnosed as having pernicious anaemia.

In the group with chronic inadequate nutrition, just under one-third had severe malnutrition; in a further half, nutrition had been severely restricted for several months, and a remaining one-quarter had taken no meat or fish for many years.

\section{DICOPAC TEST}

In the analysis of the Dicopac results, some repeat tests were included and a few patients' results had to be omitted for technical reasons.

The distribution of the ratios obtained from 260 tests is shown (Fig. 1). Ratios of over 10 were plotted as having the value 10 . One ratio result of 8.4 was omitted from the calculation of the mean ratio for normal patients $(1 \cdot 17)$ for reasons given later.

The Radiochemical Centre suggests that the upper limit of the normal range for the ratio is about 1.3 and the lower limit for PA is about $2 \cdot 0$. They describe an intermediate group of results with ratios between 1.3 and 2.0 and with total unbound vitamin $B_{12}$ excretion of over $9 \%$ but can offer no clinical explanation. A plot of ratios against ${ }^{58} \mathrm{Co}$ excretion (Fig. 2) shows that for our series there is no sharp borderline between those patients shown by other criteria to have PA and those who do not have PA; $34 \%$ of 71 results for established PA patients gave a ratio below $2 \cdot 0$ (Fig. 2). The borderline between normal and abnormal ratios that would give the minimum number of false positive and false negative results for our series seems to be $1 \cdot 4$, but the normal and PA ranges overlap and are not clearly separated as are the Radiochemical Centre results.

Knudsen and Hippe (1974) reported reduced excretion rates of free and bound $B_{12}$ in the presence of both intestinal malabsorption and renal failure. The urinary excretion of ${ }^{57} \mathrm{Co}$ was $6.5 \%$ or less with a mean of $3.5 \%$ in $31.3 \%$ of our non-PA patients with renal failure, but comparatively low ${ }^{57} \mathrm{Co}$ excretions were recorded in $10.1 \%$ of non-PA patients with normal renal functions, of whom $74 \%$ had evidence of intestinal malabsorption. We could not confirm the findings of Knudsen and Hippe that in renal failure the ${ }^{57} \mathrm{Co} /{ }^{58} \mathrm{Co}$ ratio became normal in PA. In our five PA subjects with renal failure, the ${ }^{57} \mathrm{Co} /{ }^{58} \mathrm{Co}$ urinary isotope excretion ratios ranged from 1.9 to $10 \cdot 0$.

We investigated the possibility that age affected the results by estimating the mean ratio ${ }^{57} \mathrm{Co} /{ }^{58} \mathrm{Co}$ for a number of non-PA cases whose ages were precisely known (Table 3). The numbers in some of the groups were, of course, too low for statistical 

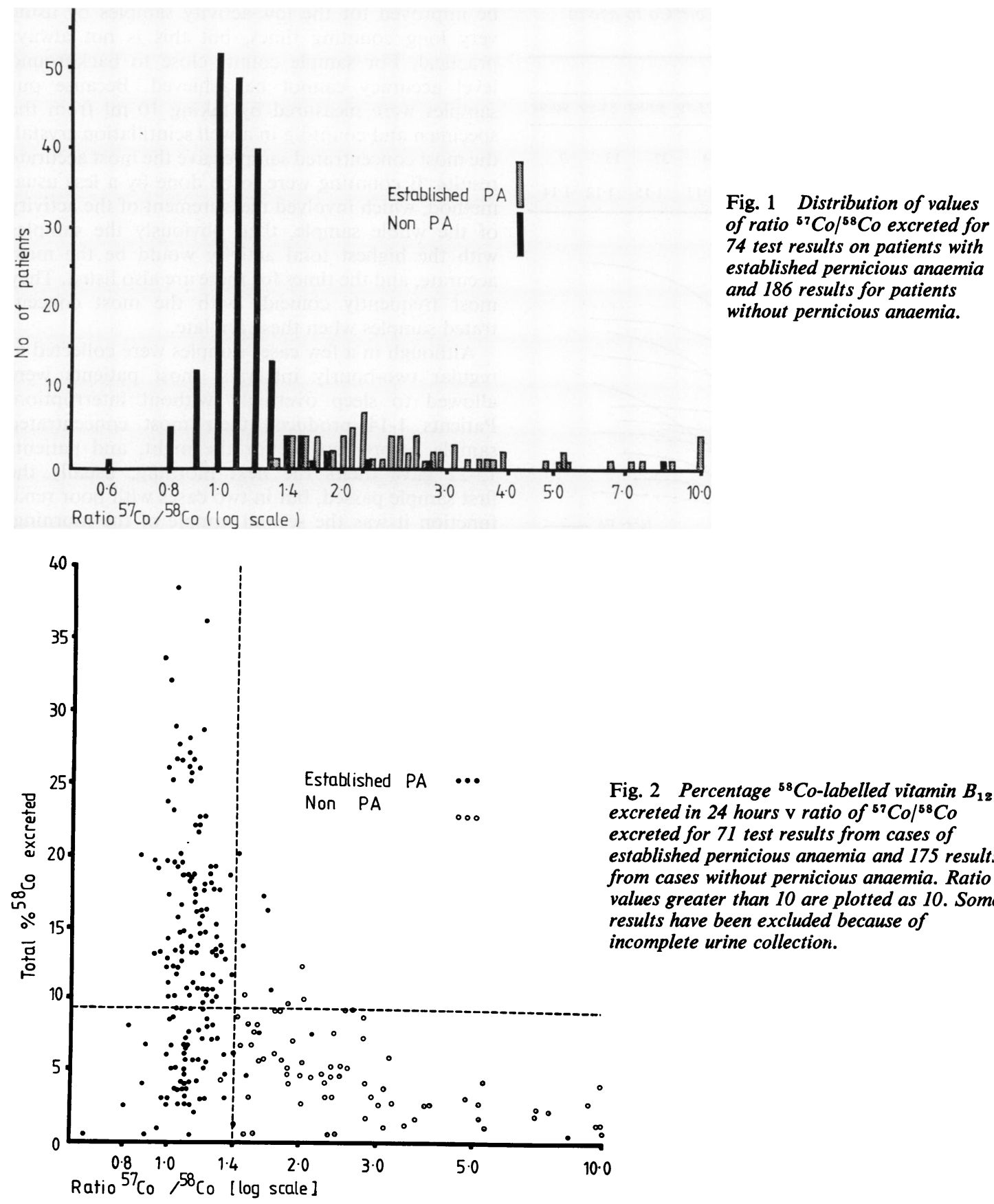

Fig. 2 Percentage ${ }^{58}$ Co-labelled vitamin $B_{12}$ excreted in 24 hours $\mathrm{v}$ ratio of ${ }^{57} \mathrm{Co} /{ }^{58} \mathrm{Co}$ excreted for 71 test results from cases of established pernicious anaemia and 175 results from cases without pernicious anaemia. Ratio values greater than 10 are plotted as 10. Some results have been excluded because of incomplete urine collection.

accuracy, but there was no obvious effect within the age range studied.

The individual urine samples collected for groups of PA and non-PA patients showed similar patterns of excretion of both isotopes, but because the ${ }^{58} \mathrm{Co}$ levels were very low for the PA patients the ${ }^{57} \mathrm{Co}$ excretion has been plotted for both groups (Fig. 3). For the sake of clarity, not all the curves obtained are shown, but there was no significant difference between the two groups. The standard deviations 
Table 3 Relation of mean ratio ${ }^{57} \mathrm{Co} /{ }^{58} \mathrm{Co}$ to age in non-PA patients

\begin{tabular}{lllllllll}
\hline \multicolumn{7}{l}{ Age (years) } \\
\cline { 2 - 7 } & $60-64$ & $65-69$ & $70-74$ & $75-79$ & $80-84$ & $85-89$ & $90-94$ \\
\hline $\begin{array}{l}\text { No. of patients } \\
\text { (non-PA) }\end{array}$ & 2 & 8 & 28 & 44 & 37 & 13 & 9 \\
$\begin{array}{l}\text { Mean ratio } \\
{ }^{87} \mathrm{Co} /{ }^{88} \mathrm{Co}\end{array}$ & 1.15 & 1.07 & 1.10 & 1.13 & 1.15 & 1.12 & 1.14 \\
\hline
\end{tabular}

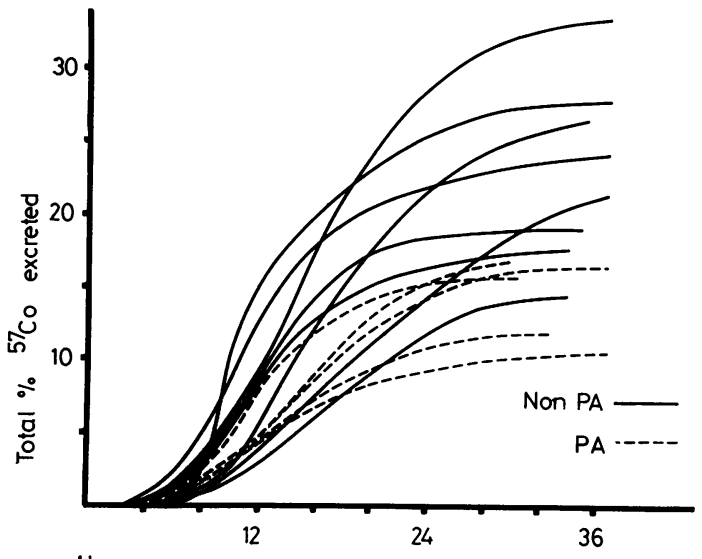

Hours

Fig. 3 Typical example of pattern of excretion of ${ }^{57}$ Co-labelled vitamin $B_{12}$ for patients with and without pernicious anaemia.

and coefficients of variation (CV) were computed for ${ }^{57} \mathrm{Co}$ level, ${ }^{58} \mathrm{Co}$ level, and the ratio ${ }^{57} \mathrm{Co} /{ }^{58} \mathrm{Co}$. Table 4 shows the times at which the most accurate measurements were made. Of course accuracy can be improved for the low-activity samples by using very long counting times, but this is not always practical. For sample counts close to background level accuracy cannot be achieved. Because our samples were measured by taking $10 \mathrm{ml}$ from the specimen and counting in a well scintillation crystal, the most concentrated sample gave the most accurate results. If counting were to be done by a less usual method, which involved measurement of the activity of the whole sample, then obviously the samples with the highest total activity would be the most accurate, and the times for these are also listed. They most frequently coincide with the most concentrated samples when these are late.

Although in a few cases samples were collected at regular two-hourly intervals, most patients were allowed to sleep overnight without interruption. Patients 1-14 produced their most concentrated sample before settling for the night, and patients 15-22 gave theirs the next morning, usually the first sample passed, but in two cases with poor renal function it was the second sample of the morning. Table 5 shows that a single sample should be ob-

Table 5 Variation of single sample accuracy with time of sampling

\begin{tabular}{lll}
\hline $\begin{array}{l}\text { Mean coefficient of } \\
\text { variation of ratio }\end{array}$ & $\begin{array}{l}\text { Hours after } \\
\text { dosing }\end{array}$ & No. of samples \\
\hline 36.98 & $0-4$ & 14 \\
$13 \cdot 10$ & $4-8$ & 34 \\
$2 \cdot 74$ & $8-12$ & 26 \\
$2 \cdot 86$ & $12-16$ & 19 \\
$2 \cdot 27$ & $16-20$ & 15 \\
$3 \cdot 17$ & $20-24$ & 25 \\
\hline
\end{tabular}

Table 4 Accuracy of single sample measurements

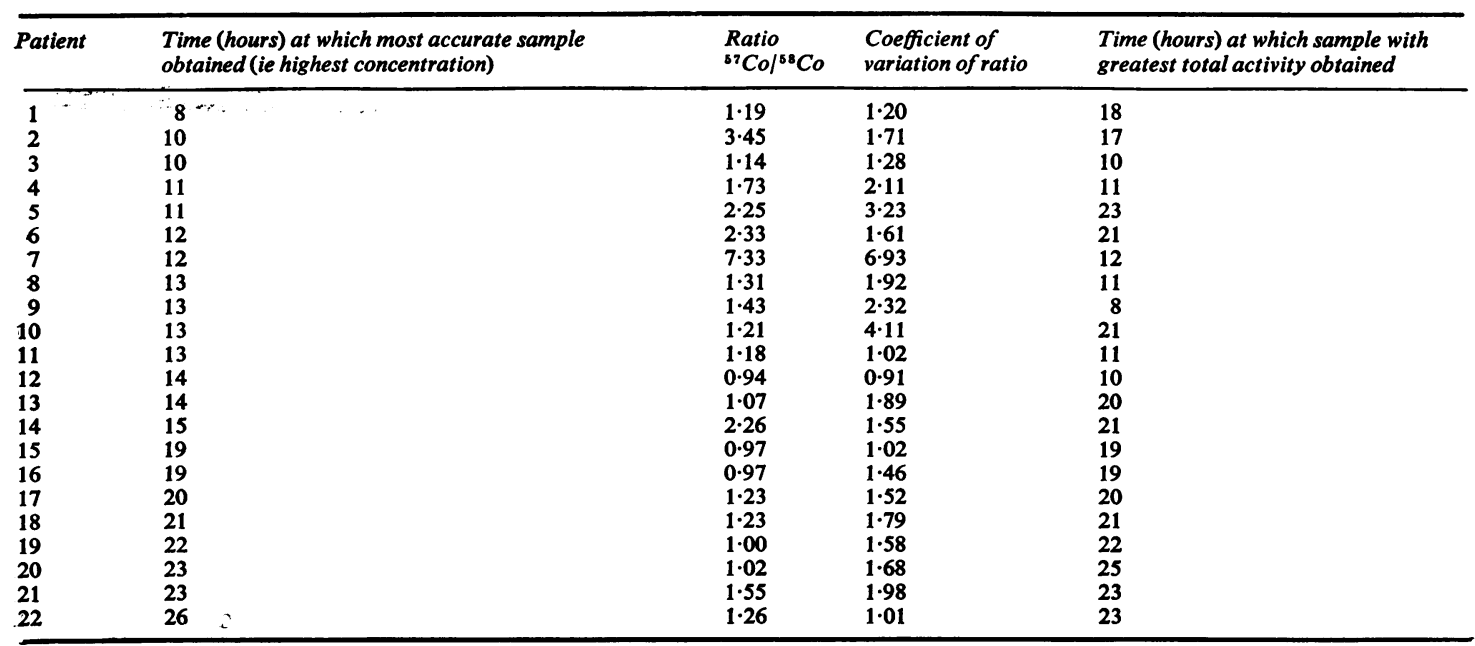


tained between 8 and 20 hours after dosing for maximum accuracy of measurement.

\section{Discussion}

Low serum $\mathrm{B}_{12}$ levels are not uncommon in old age. Of the 255 patients with low $\mathrm{B}_{12}$ levels included in this study, 71 had PA confirmed by other criteria.

In our patients, the mean serum folate level was higher in the PA group than in the non-PA group, possibly due to a disorder in the folate metabolic pathway in PA (Buchanan, 1964; Metz et al., 1968). However, in both the PA and especially in the nonPA groups concurrent low serum levels of $B_{12}$ and folate were present in a proportion of subjects. If megaloblastic marrow changes are present, the definitive diagnosis of PA may be difficult. The use of physiological doses of folic acid or of vitamin $\mathbf{B}_{12}$ is time consuming. The Dicopac test was performed in each patient in this study to evaluate its role as a diagnostic tool in subjects with low serum $B_{12}$ levels. An overlap, similar to our own, between normal and PA ranges for the ratio was reported by Payne and Finney (1972) and by Briedis et al. (1973), who recorded a borderline of $1 \cdot 5$. Their borderline for the unbound ${ }^{58} \mathrm{Co} \mathrm{B}_{12}$ excretion level was $9 \%$, and this is also the lower limit of normal quoted by the Radiochemical Centre, but four $(6 \%)$ of our PA group had excretion levels above this. We cannot have sufficient confidence in the completeness of urinary collection in our elderly patients to derive our own borderline for the total urine excretion of unbound $\mathrm{B}_{12}$. The slight skew to the distribution of the non-PA group (Fig. 1) and the fact that the mean ratio for 184 non-PA patients was 1.17 may be explained by a reduction of IF in the elderly in whom the administration of IF may produce a slight increase in absorption (Chanarin, 1969).

For our series a ratio borderline drawn at 1.4 gave only one false negative $(1.4 \%$ of the PA group) and two borderline results for PA subjects. Of 175 non-PA cases, nine $(5 \%)$ gave false positive results. Four of these had a ${ }^{58} \mathrm{Co}$ excretion level high enough to make misdiagnosis unlikely, and one with a ratio of 8.4 presents an extreme situation in which both ${ }^{58} \mathrm{Co}$ and ${ }^{57} \mathrm{Co}$ levels are barely above background counting rate so that even for very long counting times the statistics were very poor and the coefficient of variation of the ratio was 361 . This was a case of malabsorption which could account for the low excretion levels, but one cannot exclude the possibility suggested by Silberstein (1976) of a failure to administer the flushing dose of vitamin $\mathbf{B}_{12}$.

Briedis and his colleagues noted that a difference exists between the excretion levels with the dual isotope test and those obtained by the conventional Schilling test followed by repeat testing with the administration of IF. They postulate that the difference in ranges is due to a minor exchange of isotopes between the free and bound forms of vitamin $B_{12}$ in the standard Dicopac test and suggest a modification in which bound vitamin $\mathbf{B}_{12}$ is given 2 hours after the free $B_{12}$ in order to reduce this effect and to ensure better separation of normal and abnormal groups.

We regard the Dicopac test as a useful simple screening test in the differential diagnosis of patients with a megaloblastic anaemia when the serum vitamin $\mathrm{B}_{12}$ and serum folate concentrations are low in patients inappropriately given vitamin $B_{12}$ before investigations. Knudsen and Hippe's technique of doubling the oral dose of isotope and estimating the plasma activity 8 hours later appears to provide more reliable discriminatory measurements but reduces the usefulness of the test as a practical outpatient procedure. Administration of the free $B_{12}$ isotope 2 hours after the bound isotope may increase the specificity of the test (Briedis et al., 1973).

Our thanks are due to Dr R. J. Bayley of the Radiochemical Centre, Amersham for statistical help and to Mrs A. England for help with the sample measurements. We appreciate the help and suggestions offered by Professor A. Jacobs, Department of Haematology, University Hospital of Wales, Cardiff.

\section{References}

Bell, T. K., Bridges, J. M., and Nelson, M. G. (1965). Simultaneous free and bound radioactive vitamin $\mathbf{B}_{12}$ urinary excretion test. Journal of Clinical Pathology, 18, 611-613.

Briedis, D., McIntyre, P. A., Judisch, J., and Wagner, H. N., Jr. (1973). An evaluation of a dual-isotope method for the measurement of vitamin $B_{12}$ absorption. Journal of Nuclear Medicine, 14, 135-141.

Buchanan, J. M. (1964). The function of vitamin $B_{12}$ and folic acid co-enzymes in mammalian cells. Medicine, 43, 697-709.

Chanarin, I. (1969). The Megaloblastic Anaemias, pp. 216-217. Blackwell, Oxford and Edinburgh.

Cochrane, A. L., and Moore, F. (1971). Expected and observed values for the prescription of vitamin $B_{12}$ in England and Wales. British Journal of Preventive and Social Medicine, 25, 147-151.

Evans, D. M. D., Pathy, M. S., Sanerkin, N. G., and Deeble, T. J. (1968). Anaemia in geriatric patients. Gerontologia Clinica, 10, 228-241.

Halsted, J. A., Gasster, M., and Drenick, E. J. (1954) Absorption of radioactive vitamin $\mathbf{B}_{12}$ after total 
gastrectomy. New England Journal of Medicine, 251, 161-168.

Heinle, R. W., Welch, A. D., Scharf, V., Meacham, G. C., and Prusoff, W. H. (1952). Studies of excretion (and absorption) of $\mathrm{Co}^{60}$ labeled vitamin $\mathrm{B}_{12}$ in pernicious anemia. Transactions of the Association of American Physicians, 65, 214-222.

Hunter, S. H., Bach, M. K., and Ross, G. I. M. (1956). A sugar containing basal medium for vitamin $\mathbf{B}_{12}$ assay with Euglena; application to body fluids. Journal of Protozoology, 3, 101-107.

Katz, J. H., Dimase, J., and Donaldson, R. M., Jr. (1963). Simultaneous administration of gastric juice-bound and free radioactive cyanocobalamin. Rapid procedure for differentiating between intrinsic factor deficiency and other causes of vitamin $\mathbf{B}_{12}$ malabsorption. Journal of Laboratory and Clinical Medicine, 61, 266-271.

Knudsen, L., and Hippe, E. (1974). Vitamin $B_{12}$ absorption evaluated by a dual isotope test (Dicopac). Results of radioactivity measurements in plasma and in urine. Scandinavian Journal of Haematology, 13, 287-293.

Metz, J., Kelly, A., Swett, V. C., Waxman, S., and Herbert, V. (1968). Deranged DNA synthesis by bone marrow from vitamin $\mathbf{B}_{12}$-deficient humans. British Journal of Haematology, 14, 575-592.

Mollin, D. L., and Ross, G. I. N. (1957). The pathophysiology of vitamin $\mathbf{B}_{12}$ deficiency in the megaloblastic anaemias. Vitamin $\mathbf{B}_{12}$ and intrinsic factor. Europäisches Symposion, Hamburg, 1956, edited by H. C. Heinrich, p. 413. Enke, Stuttgart.
Nakamura, R. M., Ford, J., Butts, A. C., and Kunitake, G. M. (1965). Use of protein solubilizing detergent for rapid serum iron and iron combining capacity assays. American Journal of Medical Technology, 31, 403-409.

Pathy, M. S., and Davies, K. (1971). An evaluation of routine biochemical and haematological profiles in the elderly. Technicon Symposium, London.

Payne, R. W., and Finney, R. D. (1972). An evaluation of the double isotope test in the diagnosis of pernicious anaemia. Scottish Medical Journal, 17, 359-363.

Ross, G. I. M. (1952). Vitamin $B_{12}$ assay in body fluids using Euglena gracilis. Journal of Clinical Pathology, 5, 250-256.

Schilling, R. F. (1953). Intrinsic factor studies. The 2. effect of gastric juice on the urinary excretion of radioactivity after the oral administration of radioactive vitamin $\mathbf{B}_{12}$. Journal of Laboratory and Clinical Medicine, 42, 860-866.

Silberstein, E. B. (1976). Cause of abnormalities reported in nuclear medicine testing. Journal of Nuclear Medicine, 17, 229-232.

Spray, G. H., and Witts, L. J. (1958). Results of three years' experience with microbiological assay of vitamin $\mathrm{B}_{12}$ in serum. British Medical Journal, 1, 295-298.

Waters, A. H., and Mollin, D. L. (1961). Studies on the folic acid activity of human serum. Journal of Clinical Pathology, 14, 335-344.

Requests for reprints to: Dr M. S. Pathy, University Hospital of Wales, Heath Park, Cardiff CF4 4XW, UK. 